\title{
Properties and Antioxidant Capacity of Anchovy (Engraulis encrasicholus) By-Product Protein Films Containing Thyme Essential Oil
}

\author{
Serpil Tural and Sadettin Turhan* \\ Department of Food Engineering, Engineering Faculty, Ondokuz Mayis University, \\ TR-55139 Samsun, Turkey \\ Received: June 9, 2016 \\ Accepted: October 13, 2016
}

\begin{abstract}
Summary
In this study, some properties and antioxidant capacity of anchovy (Engraulis encrasicholus) by-product protein films with added $0.5,1.0$ and $1.5 \%$ of thyme essential oil were investigated. The films with thyme essential oil had higher elongation at break, water vapour permeability and oxygen permeability, lower solubility and tensile strength than control film $(\mathrm{p}<0.05)$. The incorporation of thyme essential oil affected transparency values of the films, but only the addition of $1.5 \%$ of thyme essential oil significantly reduced the transparency $(p<0.05)$. In the film matrix, molecular organisation and intermolecular interaction were changed by thyme essential oil addition. The films with thyme essential oil had a heterogeneous surface and a relatively smooth cross-section structure. Slightly higher phase transition and lower glass transition temperatures were observed in films with thyme essential oil. The antioxidant capacity of the films was improved by incorporating thyme essential oil depending on its volume fraction.
\end{abstract}

Key words: anchovy by-product protein film, thyme essential oil, water vapour permeability, mechanical properties, antioxidant capacity

\section{Introduction}

Due to the environmental impact of the excessive quantity of non-degradable waste materials, packaging studies have recently focused on developing biodegradable and/or edible packaging films obtained from natural sources, such as by-products of agriculture, fishing or livestock raising (1). Among these natural sources, proteins from fish processing by-products have been successfully utilised in the development of edible films, as reported by various researchers (2-4). A small sea fish, anchovy (Engraulis encrasicholus) is nearly $12 \mathrm{~cm}$ long with the highest catch rate among the marine fish found in Turkey $(5,6)$. Fish head, frame and viscera, as by-products, are generated by anchovy processing, and have been generally turned into by-products with low value (for example fish flour powder to be added to animal feed) or directly dis- posed into the environment, which in turn causes pollution problems (6). Therefore, it is important that fish processing by-products are effectively evaluated for the prevention of environmental pollution and obtaining high value-added products (4).

Food products can be protected by edible films and coatings against moisture migration or diffusion of the gases that have substantial role in food deterioration, such as $\mathrm{O}_{2}$ or $\mathrm{CO}_{2}$. Moreover, films and coatings can act as carriers for antioxidants, antimicrobials, nutrients, spices and herbs (1). However, due to their hydrophilic character, fish protein films are generally insufficient barriers to prevent water vapour migration, as reported by various researchers $(2,3,7,8)$. Water vapour permeability (WVP) and antioxidant properties of the films can be improved by adding active compounds such as essential oils $(2,3$, 
9,10). Among these essential oils, thyme essential oil is a key essential oil containing active compounds such as thymol and carvacrol with known antioxidant capacity (11). Various properties of chitosan films containing thyme essential oil were investigated by Altiok et al. (12), and they indicated that oxygen transmission and WVP rate of the film barely increased, while its mechanical properties decreased with the addition of thyme essential oil. Moreover, they observed an increase in the antioxidant capacity of films with the addition of thyme essential oil. Pires et al. (2) studied the characteristics of biodegradable films containing thyme essential oil and hake proteins. Their study showed that the addition of thyme essential oil to the films reduced the WVP and increased the antioxidant activity. Kavoosi et al. (13) found that the addition of thyme essential oil to gelatin films led to an important decrease in tensile strength (TS), an increase in water solubility, elongation at break (EAB) and WVP. In addition, they indicated that the films containing thyme essential oil showed perfect antioxidant properties. Jouki et al. (14) found that thyme essential oil addition to quince seed mucilage films increased the WVP and oxygen permeability $(\mathrm{OP})$, whereas decreased the glass transition temperature.

As seen from the above results, the incorporation of thyme essential oil into chitosan, hake protein, gelatin or quince seed mucilage films affected WVP, OP, water solubility, mechanical properties, glass transition temperature and antioxidant capacity. As far as we know, there is no data on the addition of thyme essential oil to anchovy by-product protein films. Therefore, this work aims to evaluate the effect of thyme essential oil, at various volume fractions, on the properties and antioxidant capacity of the anchovy by-product protein films. Thickness, solubility, transparency, WVP, OP, mechanical and other properties were determined by differential scanning calorimetry, scanning electron microscopy and Fourier-transform infrared spectroscopy. Ferric reducing antioxidant power (FRAP) and 2,2-diphenyl-1-picrylhydrazyl (DPPH) scavenging activity values of the anchovy by-product protein films containing thyme essential oil were also assessed.

\section{Materials and Methods}

\section{Anchovy by-product protein powder and essential oil preparation}

Anchovy (Engraulis encrasicholus) processing by-products (head, frame and viscera) used as material in the film production were obtained from SASTAS A.S. (Samsun, Turkey) and minced with an electronic meat mincer (model MEW 613; Mado Primus, Eilenburg, Germany). Anchovy by-product proteins were prepared, with some modifications, as reported by Zavareze et al. (4). Firstly, minced by-products were mixed with water at 1:2 ratio (by mass per volume) in a blender (Model SHB 3062; Sinbo, Istanbul, Turkey) for $1 \mathrm{~min}$. For protein solubilisation, $2 \mathrm{M} \mathrm{NaOH}(\mathrm{pH}=11.2)$ were added and the mixture was homogenised by continuous agitation with a magnetic stirrer (model HS15-03P; MTOPS, Yangju City, Kyunggido, Korea) for $1 \mathrm{~h}$. The sample was centrifuged with a laboratory centrifuge (model NF 800R; Nuve, Ankara,
Turkey) at $9000 \times g$ and $4{ }^{\circ} \mathrm{C}$ for $30 \mathrm{~min}$ in order to obtain three phases (soluble proteins, insoluble proteins and lipids). The supernatant (soluble proteins) was collected and acidified with $2 \mathrm{M} \mathrm{HCl}$ ( $\mathrm{pH}=5.35$ ) for protein precipitation. Then, it was stirred for $5 \mathrm{~min}$ and centrifuged with a laboratory centrifuge again at $9000 \times g$ and $4{ }^{\circ} \mathrm{C}$ for $15 \mathrm{~min}$. Finally, the precipitated proteins were oven-dried with forced air (model JSOF-50; JSR, Gongju City, Korea) at 35 ${ }^{\circ} \mathrm{C}$ for $24 \mathrm{~h}$, milled and stored in glass jars at $4{ }^{\circ} \mathrm{C}$ until film preparation. The protein mass fraction of anchovy by-product protein powder was $68.58 \%$, determined according to standard AOAC method 960.52 (15).

Dried thyme (Thymus vulgaris L.) was obtained from a local market (Samsun, Turkey), powdered in a coffee grinder (model 2909; Sinbo) and hydrodistilled for $3 \mathrm{~h}$ with $50 \mathrm{~g}$ of dry plant material and $500 \mathrm{~mL}$ of distilled water in a Clevenger-type device (Sesim Kimya Laboratuvar, Ankara, Turkey). Amber coloured vials were used to collect the extracted essential oil, which was dehydrated using anhydrous sodium sulphate, then stored in the dark at $4{ }^{\circ} \mathrm{C}$ until use.

\section{Preparation of films}

The films were prepared according to Limpan et al. (16), with some modifications. A mass of $4.0 \mathrm{~g}$ of anchovy by-product protein powder was mixed with $100 \mathrm{~mL}$ of distilled water, the solution $\mathrm{pH}$ was set to 11.5 using $5 \mathrm{M}$ $\mathrm{NaOH}$, and glycerol (Merck, Darmstadt, Germany) was then added at $40 \%$ (by mass of anchovy by-product protein) as plasticiser. The solution was homogenised for $5 \mathrm{~min}$ at $11600 \times \mathrm{g}$ with an Ultraturrax homogeniser (model T25; IKA, Staufen, Germany). Afterwards, it was gently stirred with a magnetic stirrer at $85^{\circ} \mathrm{C}$ for $60 \mathrm{~min}$ to completely dissolve anchovy by-product protein powder, centrifuged at $2900 \times g$ for $10 \mathrm{~min}$ and filtered to eliminate undissolved residuals and cooled to $(40 \pm 2){ }^{\circ} \mathrm{C}$. Tween 80 (Merck) at $0.05 \%$ (by volume) of essential oil was combined with the film-forming solution to help the dissolution of the essential oil, then thyme essential oil was added at 0 (as control), 0.5, 1.0 and $1.5 \%$ (by volume). These solutions were emulsified for $3 \mathrm{~min}$ at $11600 \times g$ with an Ultraturrax homogeniser. The film-forming emulsion (50 g) was placed into acrylic plates $15 \mathrm{~cm}$ in diameter, and then oven-dried (model JSOF-50; JSR) for $24 \mathrm{~h}$ at $40{ }^{\circ} \mathrm{C}$ under air circulation. Samples of dried films were taken out of the plates and conditioned to $54 \%$ relative humidity (by using a solution of saturated magnesium nitrate) within a desiccator at room temperature for 3 days. All samples were prepared in triplicate.

\section{Determination of physicochemical properties}

A digital micrometer (model 3101-25A; Insize, Jiang$\mathrm{su}, \mathrm{PR}$ China) reading to the nearest $0.001 \mathrm{~mm}$ was used to determine the film thickness. Values of each triplicate film sample were measured at 10 different locations, and then water vapour permeability, mechanical properties and transparency value of the films were calculated based on the mean thickness value.

A method used by Gennadios et al. (17) was slightly modified and applied to determine the film solubility in water. In order to determine initial dry mass, precondi- 
tioned film pieces $(20 \mathrm{~mm} \times 20 \mathrm{~mm}$ ) were left to dry for 24 $\mathrm{h}$ at $105{ }^{\circ} \mathrm{C}$. Following the agitation for $24 \mathrm{~h}$ in $50 \mathrm{~mL}$ of distilled water with sodium azide $(0.1 \%$, by mass per volume) at room temperature, the insoluble matter was separated carefully and left to dry for $24 \mathrm{~h}$ at $105{ }^{\circ} \mathrm{C}$ for the determination of final dry mass. The following equation was used to calculate the solubility in water:

$$
\text { Solubility }=\left(\frac{m_{\text {initial }}-m_{\text {final }}}{m_{\text {initial }}}\right) \cdot 100
$$

where $m_{\text {initial }}$ and $m_{\text {final }}$ are the initial and final dry mass (g), respectively. All tests were carried out in triplicate.

\section{Determination of optical properties}

Transparency value of the film was calculated by measuring the absorbance at $600 \mathrm{~nm}$ using UV-Vis spectrophotometer (model Cary 60; Agilent Technologies, Mulgrave, Australia) according to Kurt and Kahyaoglu (18). The samples were cut into rectangular pieces and placed in the spectrophotometer test cell. The reference value was determined from an empty test cell. The following equation was used to determine the transparency value of the film:

$$
\text { Transparency value }=\frac{A_{600 \mathrm{~nm}}}{\delta}
$$

where $A_{600 \mathrm{~nm}}$ is the absorbance at $600 \mathrm{~nm}$, and $\delta$ is the mean film thickness (mm). All measurements were performed in triplicate at 5 different locations.

\section{Determination of mechanical properties}

A texture analyser (TA-XT2 texture analyser; Stable Micro Systems Co., Ltd., Godalming, UK) was utilised to determine the tensile strength (TS) and elongation at break (EAB) of the films, based on ASTM D882-12 standard method (19). Sample films were sliced into strips (1 $\mathrm{cm} \times 4 \mathrm{~cm}$ ) and conditioned in $54 \%$ relative humidity $(\mathrm{RH})$ for 3 days. During the extension of the strips, force and distance were determined at $1.5 \mathrm{~mm} / \mathrm{s}$ up to break. The load at break was divided by the film cross-sectional area to calculate TS. Cross-sectional area was calculated based on the mean thickness of film strips. Elongation at the moment of rupture was divided by the initial gauge length, and then multiplied by 100 in order to calculate the $\mathrm{EAB}(\%)$. The results show the average of five samples for each type of films.

\section{Determination of barrier properties}

The water vapour permeability (WVP) values were determined according to ASTM E96 / E96M-10 standard method (20). The films ( $d=14 \mathrm{~mm})$ were sealed with paraffin on glass permeation cups containing silica gels (0\% $\mathrm{RH})$ and left in desiccators containing distilled water (100 $\% \mathrm{RH})$ at $25{ }^{\circ} \mathrm{C}$. The mass of the glass permeation cups was measured for $8 \mathrm{~h}$ at 1-hour intervals and the following equation was used to determine the WVP $((\mathrm{g} \cdot \mathrm{mm}) /$ $\left.\left(\mathrm{m}^{2} \cdot \mathrm{h} \cdot \mathrm{kPa}\right)\right)$ of the films:

$$
\mathrm{WVP}=\left(\frac{m}{t}\right) \cdot\left(\frac{\delta}{\Delta p \cdot A}\right)
$$

where $m$ is the mass gain $(\mathrm{g}), t$ is the time of gain $(\mathrm{h}), \delta$ is the film thickness $(\mathrm{mm}), \Delta p$ is the partial pressure differ- ence through the film at $25^{\circ} \mathrm{C}(\mathrm{kPa})$ and $A$ is the film area exposed to moisture transfer $\left(1.539 \cdot 10^{-4} \mathrm{~m}^{2}\right)$. The $\mathrm{m} / \mathrm{t}$ was determined via linear regression $\left(R^{2}>0.99\right)$ based on the mass of water absorbed by the system at the steady state. All values were determined in triplicate for each film type.

Oxygen permeability (OP) was determined based on the peroxide value (PV) using AOCS Cd 8-53 method (21). Briefly, a $25-\mathrm{mL}$ tube was filled with $10 \mathrm{~mL}$ of sunflower oil, covered with films containing thyme essential oil, sealed using paraffin and sticky tape, and stored at a controlled temperature $\left(60{ }^{\circ} \mathrm{C}\right)$ for 10 days. The PV of the sunflower oil samples was determined by titration with sodium thiosulfate. All values were determined in triplicate for each film type.

\section{Fourier-transform infrared spectroscopy measurements}

Fourier-transform infrared (FTIR) spectra of the samples were measured using a FTIR spectrometer (model Spectrum Two; PerkinElmer, Akron, OH, USA) at $4 \mathrm{~cm}^{-1}$ resolution within a range of $650-4000 \mathrm{~cm}^{-1}$. Before the analysis, the samples were left at room temperature in a desiccator containing silica gel for two weeks to obtain the highest dehydration. For each spectrum 32 scans were run.

\section{Scanning electron microscopy determination}

Scanning electron microscope (model JSM-7001F; JEOL, Tokyo, Japan) was utilised at $10 \mathrm{kV}$ to determine the surface and cross-section characteristics of the samples. Before the visualisation process, sputter coater with gold/palladium (model SC7620; Quorum Technologies, Laughton, UK) was used to coat the films, and surface and cross-section photographs were taken at 1500 and 4000× magnification, respectively.

\section{Differential scanning calorimetry measurements}

Thermal properties of the samples were measured via a differential scanning calorimeter (model DSC 4000; PerkinElmer). Before the analysis, film samples were stored at room temperature for two weeks in a desiccator with silica gel to dehydrate. A sample weighing $5 \mathrm{mg}$ was sealed in aluminium pans, and then scanned under a nitrogen atmosphere at $10{ }^{\circ} \mathrm{C}$ per min over the range of -50 to 120 ${ }^{\circ} \mathrm{C}$.

\section{Antioxidant capacity determination}

Antioxidant capacity of anchovy by-product protein films containing thyme essential oil was determined using the ferric reducing antioxidant power (FRAP) method (22) and 2,2-diphenyl-1-picrylhydrazyl (DPPH) scavenging activity method (23).

For the FRAP determination, $1.5 \mathrm{~mL}$ of methanol was used to dissolve $0.15 \mathrm{~g}$ of anchovy by-product protein film, and then $50 \mu \mathrm{L}$ of film extract solution were added to $0.95 \mathrm{~mL}$ of FRAP reagent prepared by mixing $300 \mathrm{mM}$ acetate buffer $(\mathrm{pH}=3.6), 20 \mathrm{mM} \mathrm{FeCl}_{3}$ and a solution of 10 $\mathrm{mM}$ ferric-2,4,6-tripyridil-s-triazine (TPTZ) in $40 \mathrm{mM} \mathrm{HCl}$ at the ratio of 10:1:1. The absorbance was determined at $593 \mathrm{~nm}$ by UV-Vis spectrophotometer (Model Cary 60; 
Agilent Technologies). Trolox standard curves were used to calculate FRAP values, which were expressed in mg of Trolox per $\mathrm{mL}$ of film.

For the DPPH scavenging activity determination, 10 $\mu \mathrm{L}$ of film extract solution, obtained by dissolving $0.15 \mathrm{~g}$ of film in $1.5 \mathrm{~mL}$ of methanol, were added to $1 \mathrm{~mL}$ of DPPH in methanol solution $(60 \mu \mathrm{M})$ and $40 \mu \mathrm{L}$ of methanol. After firmly shaking the mixture, it was left at room temperature in the dark for $30 \mathrm{~min}$. The absorbance was determined at $517 \mathrm{~nm}$. All reagents, except for the sample, were used to prepare a negative control. Following equation was employed to calculate the DPPH scavenging activity:

$$
\text { DPPH scavenging activity }=\left(\frac{A_{\text {control }}-A_{\text {sample }}}{A_{\text {control }}}\right) \cdot 100
$$

where $A_{\text {control }}$ is the absorbance of the control, and $A_{\text {sample }}$ is the absorbance of the sample.

\section{Statistical analysis}

All experiments were performed in triplicate and the values were presented as mean \pm standard deviation. Data of physical, optical, mechanical and barrier properties, and antioxidant capacity were determined using the analysis of variance (ANOVA) and the comparison of the mean values was done using Duncan's multiple range test. SPSS statistical package program v. 17.0 for Windows (SPSS Inc., Chicago, IL, USA) was utilised with a significance level at $\mathrm{p}=0.05$.

\section{Results and Discussion}

\section{Physicochemical properties of films}

Table 1 shows the physicochemical properties of anchovy by-product protein films containing thyme essential oil at various volume fractions. The sample thickness ranged from 0.197 to $0.202 \mathrm{~mm}$, and the addition of thyme essential oil did not have a significant $(p>0.05)$ effect on the resulting film thickness. Altiok et al. (12) reported similar results in the chitosan films with thyme essential oil, and Bahram et al. (10) also obtained similar results in the whey protein films prepared with 0.8 and $1.5 \%$ cinnamon essential oil. However, Jouki et al. (14) showed that the addition of thyme essential oil increased the thickness of quince seed mucilage films, but significant increase was only obtained at the highest thyme essential oil level used ( $2 \%$ ). These different results could be attributed to the solid content of film-forming solutions.

Solubility is one of the important properties of edible films, due to its effect on the film resistance to water, in particular in humid environments (24). As seen in Table 1, the films containing thyme essential oil were less soluble than the control film $(\mathrm{p}<0.05)$, but differences between solubility values of films containing different volume fractions of thyme essential oil were not significant ( $p>0.05)$. A decrease in the hydrophilic nature of the sample may have led to these results. According to Kavoosi et al. (13), the type and concentration of compounds and their inherent hydrophilicity and hydrophobicity indices alter their additive effect on the film solubility. Decreased solubility with the addition of different essential oils was also determined by various researchers $(3,10,24-26)$.

\section{Optical properties of films}

Consumer preference is directly affected by optical properties of edible films used as food packaging materials (27). As seen in Table 1, the addition of thyme essential oil affected the transparency values of anchovy by-product protein films, and only the addition of $1.5 \%$ thyme essential oil reduced transparency $(p<0.05)$, which was verified by higher transparency value. The decrease in transparency could be attributed to the increase in light scattering caused by oil droplets in the film network. In addition, the colour components in thyme essential oil probably contributed to the decrease of film transparency and films containing thyme essential oil became less transparent. Similar results were obtained by Pires et al. (2) for hake protein films containing thyme essential oil, by Tongnuanchan et al. (28) for fish skin gelatin films containing plai, turmeric and ginger essential oils and by Hosseini et al. (29) for fish gelatin chitosan biocomposite films containing oregano essential oil.

\section{Mechanical properties of film samples}

Mechanical properties of the samples were determined based on the TS and EAB values, the key indicators of film flexibility and strength (25). Table 1 shows the TS and EAB values of anchovy by-product protein films

Table 1. Physicochemical, optical, mechanical and barrier properties of anchovy by-product protein films with thyme essential oil

\begin{tabular}{|c|c|c|c|c|}
\hline \multirow{2}{*}{ Property } & \multicolumn{4}{|c|}{$\varphi($ thyme essential oil) $/ \%$} \\
\hline & 0 (control) & 0.5 & 1.0 & 1.5 \\
\hline Thickness/mm & $(0.20 \pm 0.01)^{\mathrm{a}}$ & $(0.199 \pm 0.002)^{\mathrm{a}}$ & $(0.197 \pm 0.006)^{\mathrm{a}}$ & $(0.202 \pm 0.003)^{\mathrm{a}}$ \\
\hline Solubility/\% & $(63.4 \pm 0.4)^{\mathrm{a}}$ & $(59.2 \pm 1.5)^{\mathrm{b}}$ & $(59.16 \pm 0.03)^{\mathrm{b}}$ & $(56.2 \pm 2.7)^{\mathrm{b}}$ \\
\hline Transparency & $(1.28 \pm 0.01)^{\mathrm{b}}$ & $(1.27 \pm 0.06)^{\mathrm{b}}$ & $(1.31 \pm 0.03)^{\mathrm{b}}$ & $(1.46 \pm 0.02)^{\mathrm{a}}$ \\
\hline Tensile strength/MPa & $(1.46 \pm 0.04)^{\mathrm{a}}$ & $(0.55 \pm 0.09)^{\mathrm{b}}$ & $(0.47 \pm 0.01)^{\mathrm{b}}$ & $(0.52 \pm 0.02)^{b}$ \\
\hline Elongation at break/\% & $(51.5 \pm 2.2)^{\mathrm{b}}$ & $(79.6 \pm 7.2)^{\mathrm{a}}$ & $(83.4 \pm 6.8)^{\mathrm{a}}$ & $(80.1 \pm 4.8)^{\mathrm{a}}$ \\
\hline Water vapour permeability $/\left((\mathrm{g} \cdot \mathrm{mm}) /\left(\mathrm{m}^{2} \cdot \mathrm{h} \cdot \mathrm{kPa}\right)\right)$ & $(1.5 \pm 0.1)^{b}$ & $(2.08 \pm 0.07)^{\mathrm{a}}$ & $(2.12 \pm 0.02)^{\mathrm{a}}$ & $(2.0 \pm 0.2)^{\mathrm{a}}$ \\
\hline Oxygen permeability/(mmol/kg) & $(14.0 \pm 1.1)^{\mathrm{b}}$ & $(16.6 \pm 0.2)^{\mathrm{a}}$ & $(16.5 \pm 2.6)^{\mathrm{a}}$ & $(15.92 \pm 2.04)^{\mathrm{a}}$ \\
\hline
\end{tabular}

The results represent mean values \pm standard deviation of three replicates. Values in the same row with different letters in superscript are significantly different $(\mathrm{p}<0.05)$ 
containing thyme essential oil at different volume fractions $(0.5,1.0$ and $1.5 \%)$. According to the results, control film had the highest TS and the lowest EAB $(\mathrm{p}<0.05)$ compared to others. On the other hand, no changes were observed in the TS and EAB values in films containing 0.5, 1.0 and $1.5 \%$ thyme essential oil ( $p>0.05)$. Results showed that a $64 \%$ reduction in the TS values $(1.46-0.52 \mathrm{MPa})$ was obtained by the addition of $1.5 \%$ thyme essential oil to the anchovy by-product protein films. The addition of essential oils into films may reinforce the development of heterogeneous film matrix, which may in turn lead to discontinuity in the film network $(9,28)$. Addition of essential oils to protein-based films could prevent protein-protein interaction and produce flexible domains within the film (9). Moreover, these changes could be attributed to plasticising effect of the thyme essential oil (14). As a result, films containing thyme essential oil became weaker, with lower TS, but more stretchable. Jouki et al. (14) observed an increase in the EAB and a decrease in TS of quince seed mucilage films containing thyme essential oil, which is in line with the results of this study. Similarly, Shojaee-Aliabadi et al. (26) found that the addition of Satureja hortensis essential oil into $\mathrm{K}$-carrageenan film caused a significant $(\mathrm{p}<0.05)$ decrease of TS and increase of EAB. Increases of $\mathrm{EAB}$ and decreases of TS are typical results of essential oil addition, which have been largely handled in the research on various edible films $(9,25,27-29)$.

\section{Barrier properties of films}

Water and oxygen are important compounds whose migration needs to be controlled, because physical and chemical changes in foods are usually created by the transfer of moisture and oxygen between the food and its surrounding atmosphere (29). Table 1 shows the WVP values of anchovy by-product protein films containing various volume fractions of thyme essential oil. The addition of thyme essential oil to anchovy by-product protein films increased the WVP values from 1.5 to $2.12(\mathrm{~g} \cdot \mathrm{mm}) /\left(\mathrm{m}^{2} \cdot \mathrm{h} \cdot \mathrm{kPa}\right)$ $(p<0.05)$, but significant differences were not detected between the films containing various volume fractions of thyme essential oil ( $p>0.05)$. Many factors such as the ratio of hydrophilic and hydrophobic film components, film thickness, water sensitivity and crystallinity can change the WVP values of the films (14). The increase in the WVP values of the films containing essential oil can be attributed to the discontinuities, caused by lipid droplets in the polymer network leading to a loss in film cohesion and therefore enhancing the transport of water vapour through the film (29,30). Additionally, this may also be due to the ratio of hydrophilic and hydrophobic film constituents, directly influencing the transfer of water vapour through the film network (29). Altiok et al. (12) showed that WVP of chitosan films containing thyme essential oil barely increased compared to the control film, Jouki et al. (14) found a significant increase in the WVP of quince seed mucilage films containing thyme essential oil and in another study, Hosseini et al. (29) found that the addition of oregano essential oil into fish gelatin/chitosan films also increased WVP values of the films, all of which is consistent with the present results. In contrast, some researchers found that the incorporation of essential oils into edible films improved WVP of the films $(3,9,25,26)$. These differences could be attributed to the above-mentioned factors.
In this study, OP value of the control film, measured as $\mathrm{PV}$, was determined to be $14.0 \mathrm{mmol}$ of $\mathrm{O}_{2}$ per $\mathrm{kg}$. The incorporation of thyme essential oil into the anchovy by-product protein films significantly increased $(p<0.05)$ this value, which can be explained by higher oxygen solubility in non-polar oil phase that contributes to the increase of the transfer rate of oxygen molecules into plasticised polymer matrix (14). Additionally, this behaviour could be attributed to the irregularities in the film matrix. Altiok et al. (12) reported similar results in chitosan films containing various amounts of thyme essential oil, Jouki et al. (14) also found similar results in quince seed mucilage films containing 1.5 and $2 \%$ thyme essential oil, and Ghasemlou et al. (25) reported similar results in corn starch films containing $3 \%$ Zataria multiflora Boiss essential oil.

\section{Results of Fourier-transform infrared spectroscopy}

Anchovy by-product protein and thyme essential oil interaction was investigated with FTIR spectroscopy. The FTIR spectra of control film and films containing 0.5, 1.0 and $1.5 \%$ thyme essential oil are shown in Fig. 1. The peak around $1043 \mathrm{~cm}^{-1}$ was observed in all films, corresponding to the $\mathrm{OH}$ group, primarily from glycerol incorporated as a plasticiser $(28,29)$. Increasing thyme essential oil volume fraction probably resulted in the dilution of glycerol and decrease of the peak amplitude. Tongnuanchan et al. (28) also found similar spectra for fish skin gelatin films containing ginger, turmeric and plai essential oils, where $\mathrm{OH}$ group was observed at the wavenumber $(v)$ of $1031-1035 \mathrm{~cm}^{-1}$. All films had major peaks at $v=1624-1628$ $\mathrm{cm}^{-1}$ (amide I, representing $\mathrm{C}=\mathrm{O}$ stretching/hydrogen bonding coupled with COO), $1542-1547 \mathrm{~cm}^{-1}$ (amide II, resulting from bending vibration of $\mathrm{NH}$ groups and stretching vibrations of CN groups) and $1235-1237 \mathrm{~cm}^{-1}$ (amide III, illustrating the in-plane bending vibrations of $\mathrm{CN}$ and $\mathrm{NH}$ groups of bound amide or vibrations of $\mathrm{CH}_{2}$ groups of glycine) $(9,28)$. Similar results were also found by Arfat et al. (9) for fish protein isolate/fish skin gelatin films with zinc oxide nanoparticles and basil leaf essential oil, where amide I, amide II and amide III peaks were observed at $v=1631,1537$ and $1238 \mathrm{~cm}^{-1}$, respectively. In general, the

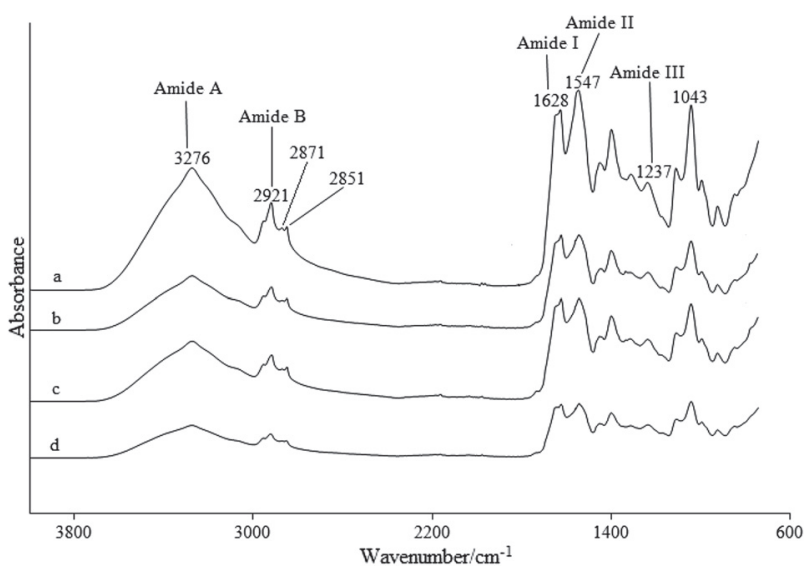

Fig. 1. FTIR spectra of anchovy by-product protein films containing thyme essential oil $\varphi($ TEO $) / \%$ : $a=$ control, $b=0.5, c=1.0$ and $\mathrm{d}=1.5$ 
amplitudes of the films decreased as the thyme essential oil volume fraction increased and the highest amplitudes for amides I, II and III were determined in control films, probably because of the highest protein content.

For all film samples, an amide A peak (representing the $\mathrm{NH}$ stretching coupled with hydrogen bonding) was found at $v=3273-3276 \mathrm{~cm}^{-1}$ and an amide B peak (representing $\mathrm{CH}$ stretching and $\mathrm{NH}_{3}^{+}$) was found at $v=2919$ $2923 \mathrm{~cm}^{-1}$. The amplitude of amide A peak decreased when thyme essential oil was added to the films, especially at $1.5 \%$ volume fraction. This certified the lower interaction among anchovy by-product proteins, shown by the lower TS of the film with the increasing $\mathrm{EAB}$, when higher volume fractions of thyme essential oil were added. Similar results for fish skin gelatin films containing ginger, turmeric and plai essential oils were also reported (28). Peaks at $v=2851 \mathrm{~cm}^{-1}$ (methylene symmetric $\mathrm{CH}$ stretching) and $2871 \mathrm{~cm}^{-1}$ (methyl asymmetric $\mathrm{CH}$ stretching) were also found in all film samples. The amplitude of the peak at $v=2871 \mathrm{~cm}^{-1}$ decreased, while the amplitude of the peak at $v=2851 \mathrm{~cm}^{-1}$ increased when thyme essential oil was incorporated into films. It was reported that symmetric methylene stretching bands approx. at $v=2851 \mathrm{~cm}^{-1}$ were present in most of the lipids, while asymmetric methyl stretching bands approx. at $v=2871 \mathrm{~cm}^{-1}$ were present in most of the proteins $(9,28,31)$. Similar results in gelatin films containing ginger, turmeric and plai essential oils and in fish gelatin films containing basil and citronella essential oils have been reported $(28,31)$. Hence, the FTIR spectrum results indicated that the addition of thyme essential oil into anchovy by-product protein films affected the molecular organisation and intermolecular interaction in polymer matrix.

\section{Results of scanning electron microscopy observations}

Scanning electron microscopy (SEM) images of the surface and cross-section of anchovy by-product protein films containing thyme essential oil are shown in Fig. 2. The control film showed a homogeneous and continuous surface (Fig. 2a), while the anchovy by-product protein films containing thyme essential oil had a heterogeneous surface (Figs. 2b-d). In addition, many granules were observed on the surface of anchovy by-product protein films containing thyme essential oil, and in general, the size of the granules increased as the essential oil volume fraction increased. This showed that the essential oil droplets were still unstable in emulsion systems stabilised by Tween 80 . Consequently, the permeability of the surface containing granules was facilitated and resulted in an increase in WVP and OP values of anchovy by-product protein films containing thyme essential oil.

The control film had a heterogeneous, rough and compact cross-section structure (Fig. 2e), while films containing thyme essential oil had a relatively smooth cross-section structure (Figs. $2 \mathrm{f}-\mathrm{h}$ ). With the addition of thyme essential oil, cross-section structure probably softened, which could be responsible for the higher WVP and OP values of the films containing thyme essential oil. Various researchers reported that the surface and cross-section structure of edible films were affected by both addition and volume fraction of essential oils $(12,29,30)$. Jouki et al. (14) also reported similar results when thyme essential oil was added into the quince seed mucilage films.

\section{Differential scanning calorimetry analysis}

Film transitions were determined by differential scanning calorimetry (DSC) when thermal changes occurred in the film (31). DSC thermograms of anchovy by-product protein films containing thyme essential oil are shown in Fig. 3. All thermograms showed endothermic peaks at the phase transition temperature $\left(t_{\mathrm{m}}\right)$ ranges of 53.53-58.04 ${ }^{\circ} \mathrm{C}$. These peaks are probably related to the denaturation temperature of myosin and actin proteins (7). Da Rocha et al. (7), in their studies with Argentine anchovy (Engraulis encrasicholus) protein isolate, observed the endothermic peak at $62.2{ }^{\circ} \mathrm{C}$. Altiok et al. (12) reported that chitosan films with or without thyme essential oil had wide endothermic peaks nearly at $35-140{ }^{\circ} \mathrm{C}$. Temperature differences of endothermic peaks could be attributed to the type of film or essential oil, the oil quality and volume
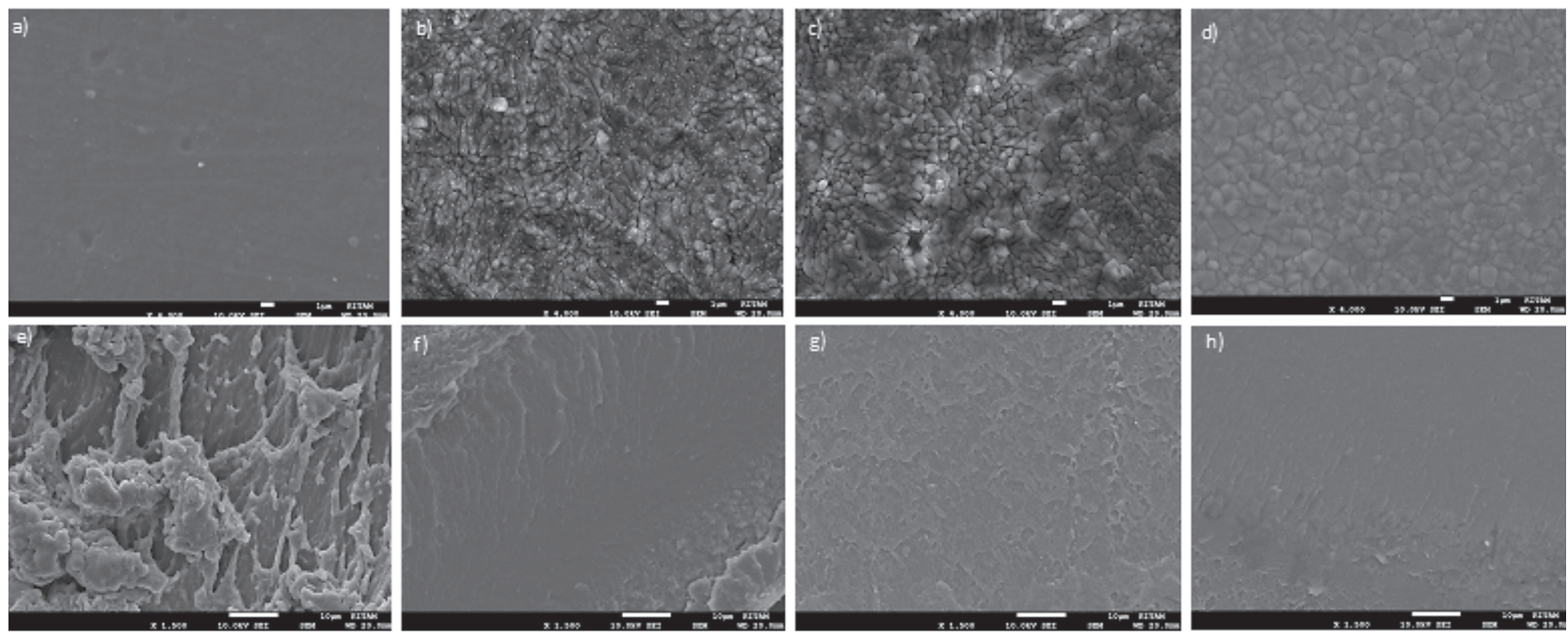

Fig. 2. SEM images of the surface: $\varphi($ TEO)/\%: a) control, b) 0.5 , c) 1.0 and d) 1.5 , and cross-section: e) control, f) 0.5 , g) 1.0 and h) 1.5 of anchovy by-product protein films containing thyme essential oil (TEO) 


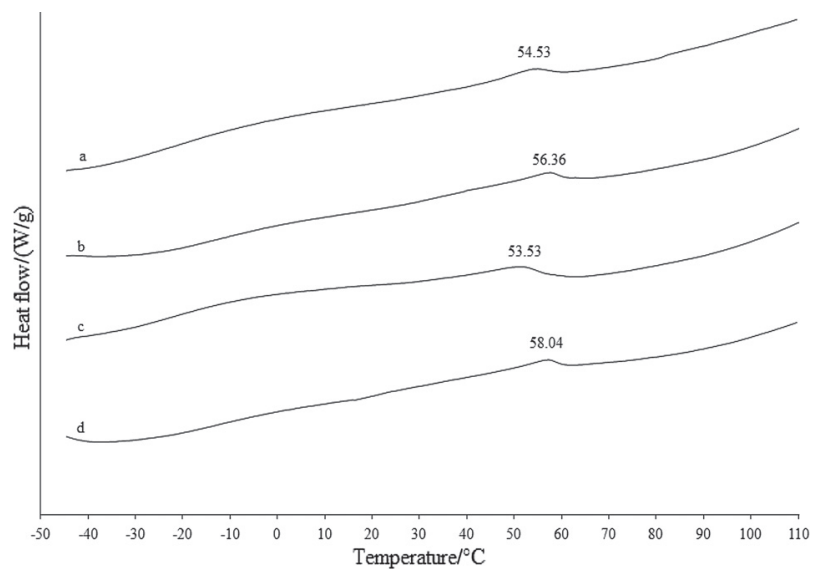

Fig. 3. Differential scanning calorimetry thermograms of anchovy by-product protein films containing thyme essential oil $\varphi($ TEO $) / \%$ : $a=$ control, $b=0.5, c=1.0$ and $d=1.5$

fraction, and heating conditions. Except for the film containing $1.0 \%$ thyme essential oil, anchovy by-product protein films with thyme essential oil had slightly higher $t_{\mathrm{m}}$ than the control film, which might be attributed to more hydrophobic nature and larger molecular mass of thyme essential oil. Jouki et al. (14) found similar results in quince seed mucilage films containing thyme essential oil, and Tongnuanchan et al. (31) also observed similar results for fish gelatin films containing basil and citronella essential oils.

The highest glass transition temperature $\left(t_{\mathrm{g}}\right)$ of -24.27 ${ }^{\circ} \mathrm{C}$ was obtained in control film and the addition of $0.5 \%$ thyme essential oil into the anchovy by-product protein films caused a decrease in $t_{\mathrm{g}}$ to $-32.82^{\circ} \mathrm{C}$ (data not shown). However, $t_{\mathrm{g}}$ of films containing 1.0 and $1.5 \%$ thyme essential oil most likely became too low, thus could not be observed in the tested temperature range. Lower $t_{\mathrm{g}}$ is better for film flexibility, and results showed that films containing thyme essential oil had lower $t_{\mathrm{g}}$, indicating better flexibility than the control sample. Moreover, Jouki et al. (14) found that pure quince seed mucilage film had $t_{\mathrm{g}}$ of $-35.2{ }^{\circ} \mathrm{C}$, which is higher than of the same film containing thyme essential oil $\left(t_{\mathrm{g}}=-43\right.$ to $\left.-57^{\circ} \mathrm{C}\right)$.

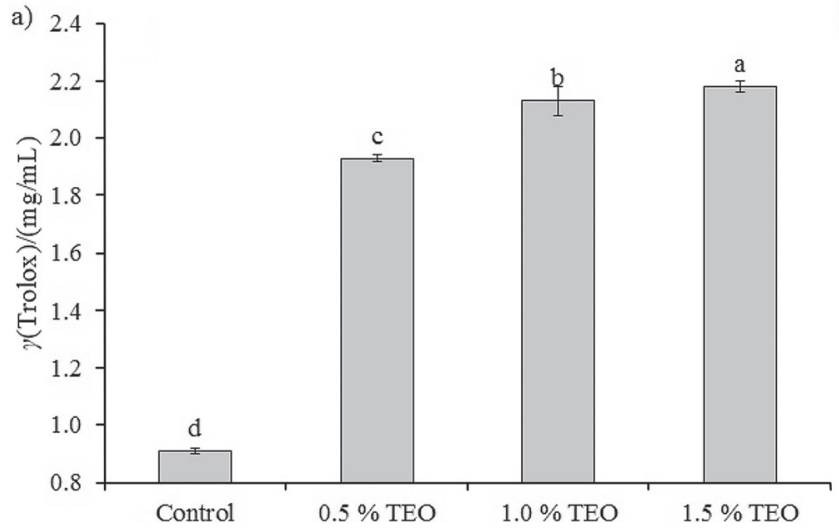

\section{Antioxidant capacity of films}

FRAP and DPPH scavenging activity values of anchovy by-product protein films containing various volume fractions of thyme essential oil are shown in Fig. 4. The lowest FRAP value $(0.91 \mathrm{mg} / \mathrm{mL}$, expressed as Trolox equivalents, Fig. 4a) was observed in the control film, and it significantly increased $(p<0.05)$ with the increase of the volume fraction of thyme essential oil from 0.5 to $1.5 \%$. Like FRAP value, the lowest DPPH scavenging activity value $(0.06 \%)$ was determined in the control film, and it significantly increased $(\mathrm{p}<0.05)$ with the increase of the thyme essential oil volume fraction. However, no significant differences were detected between the films containing 1.0 and $1.5 \%$ thyme essential oil ( $>>0.05$ ) (Fig. $4 b$ ). Lower FRAP and DPPH scavenging activity values could be attributed to free sulfhydryl groups and amino acids of anchovy by-product protein such as tryptophan, methionine and tyrosine (32). Effect of thyme essential oil on the antioxidant capacity of chitosan films was discussed by Altiok et al. (12) and Bonilla et al. (30), by Espitia et al. (33) in edible açai films and Jouki et al. (14) in quince seed mucilage films. Similar results were also shown for hake protein films containing thyme essential oil (2). The antioxidant capacity of thyme essential oil may be explained by its thymol and carvacrol content, two phenolic compounds with known antioxidant capacity (11). The results indicated that anchovy by-product protein films containing thyme essential oil could be used for the packaging of foods as active films with antioxidant activity.

\section{Conclusions}

Addition of thyme essential oil affected the solubility, transparency, mechanical properties, water vapour permeability (WVP), oxygen permeability (OP), FTIR spectra, texture and thermal properties of the films. The addition of thyme essential oil into anchovy by-product protein films decreased the solubility and tensile strength values, but increased the elongation at break, WVP and OP values. The increase in WVP and OP values of the films might limit their application in foods. However, increasing the volume fraction of thyme essential oil did not lead to significant changes in these properties. Film containing $1.5 \%$ thyme essential oil became more opaque b)

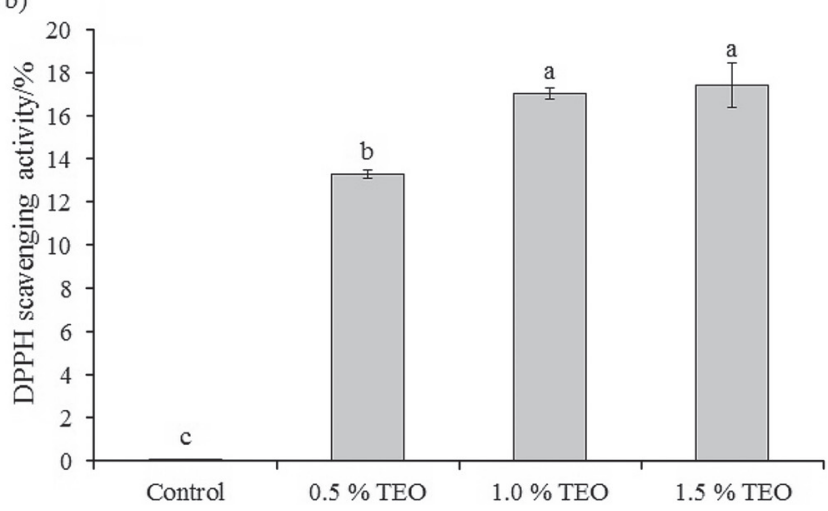

Fig. 4. Antioxidant capacity of anchovy by-product protein films containing thyme essential oil (TEO) measured by: a) FRAP as Trolox equivalents, and b) DPPH scavenging activity. Bars represent mean values \pm standard deviation of three replicates, different letters on the bars indicate significant differences $(p<0.05)$ 
than other films. The antioxidant capacity of anchovy by-product protein films was considerably improved by the addition of thyme essential oil. These results showed that the addition of thyme essential oil into the anchovy by-product protein films is suitable for developing antioxidant films. However, research on the assessment of the antimicrobial properties of these films is also required for their practical applicability.

\section{Acknowledgements}

Part of this study was taken from Serpil Tural's PhD thesis and supported by the Scientific and Technological Research Council of Turkey (TUBITAK) (Project no. 1140854). The authors would like to thank TUBITAK for financial support.

\section{References}

1. Gómez-Estaca J, Bravo L, Gómez-Guillén MC, Alemán A, Montero P. Antioxidant properties of tuna-skin and bovinehide gelatin films induced by the addition of oregano and rosemary extracts. Food Chem. 2009;112:18-25. http://dx.doi.org/10.1016/j.foodchem.2008.05.034

2. Pires C, Ramos C, Teixeira G, Batista I, Mendes R, Nunes L, Marques A. Characterization of biodegradable films prepared with hake proteins and thyme oil. J Food Eng. 2011;105:422-8. http://dx.doi.org/10.1016/j.jfoodeng.2011.02.036

3. Teixeira B, Marques A, Pires C, Ramos C, Batista I, Saraiva JA, Nunes ML. Characterization of fish protein films incorporated with essential oils of clove, garlic and origanum: physical, antioxidant and antibacterial properties. LWT Food Sci Technol. 2014;59:533-9. http://dx.doi.org/10.1016/j.lwt.2014.04.024

4. Zavareze ER, Mello El Halal SL, Marques e Silva R, Guerra Dias AR, Prentice-Hernández C. Mechanical, barrier and morphological properties of biodegradable films based on muscle and waste proteins from the whitemouth croaker (Micropogonias furnieri). J Food Process Preserv. 2014;38: 1973-81. http://dx.doi.org/10.1111/jfpp.12173

5. Ustun NS, Turhan S. Variation of physical and chemical properties of anchovies (Engraulis encrasicolus) with different length during fishing period. Gida. 1997;22:295-9 (in Turkish).

6. Temiz H, Ustun NS, Turhan S, Aykut U. Partial purification and characterization of alkaline proteases from the Black Sea anchovy (Engraulis encrasicholus) digestive tract. Afr J Biotechnol. 2013;12:56-63. http://dx.doi.org/10.5897/AJB12.2900

7. da Rocha M, Loiko MR, Gautério GV, Tondo EC, Prentice C. Influence of heating, protein and glycerol concentrations of film-forming solution on the film properties of Argentine anchovy (Engraulis anchoita) protein isolate. J Food Eng. 2013; 116:666-73. http://dx.doi.org/10.1016/j.jfoodeng.2013.01.004

8. da Rocha M, Loiko MR, Tondo EC, Prentice C. Physical, mechanical and antimicrobial properties of Argentine anchovy (Engraulis anchoita) protein films incorporated with organic acids. Food Hydrocolloid. 2014;37:213-20. http://dx.doi.org/10.1016/j.foodhyd.2013.10.017

9. Arfat YA, Benjakul S, Prodpran T, Sumpavapol P, Songtipya P. Properties and antimicrobial activity of fish protein isolate/fish skin gelatin film containing basil leaf essential oil and zinc oxide nanoparticles. Food Hydrocolloid. 2014;41: $265-73$.

http://dx.doi.org/10.1016/j.foodhyd.2014.04.023
10. Bahram S, Rezaei M, Soltani M, Kamali A, Ojagh SM, Abdollahi M. Whey protein concentrate edible film activated with cinnamon essential oil. J Food Process Preserv. 2014;38:12518. http://dx.doi.org/10.1111/jfpp.12086

11. Ruberto G, Baratta MT. Antioxidant activity of selected essential oil components in two lipid model systems. Food Chem. 2000;69:167-74. http://dx.doi.org/10.1016/S0308-8146(99)00247-2

12. Altiok D, Altiok E, Tihminlioglu F. Physical, antibacterial and antioxidant properties of chitosan films incorporated with thyme oil for potential wound healing applications. J Mater Sci Mater Med. 2010;21:2227-36. http://dx.doi.org/10.1007/s10856-010-4065-x

13. Kavoosi G, Dadfar SMM, Purfard AM. Mechanical, physical, antioxidant, and antimicrobial properties of gelatin films incorporated with thymol for potential use as nano wound dressing. J Food Sci. 2013;78:E244-50. http://dx.doi.org/10.1111/1750-3841.12015

14. Jouki M, Mortazavi SA, Yazdi FT, Koocheki A. Characterization of antioxidant-antibacterial quince seed mucilage films containing thyme essential oil. Carbohydr Polym. 2014;99: $537-46$. http://dx.doi.org/10.1016/j.carbpol.2013.08.077

15. AOAC Official Method 960.52. Microchemical determination of nitrogen (micro-Kjeldahl method). Rockville, MD, USA: AOAC International; 2000.

16. Limpan N, Prodpran T, Benjakul S, Prasarpran S. Properties of biodegradable blend films based on fish myofibrillar protein and polyvinyl alcohol as influenced by blend composition and pH level. J Food Eng. 2010;100:85-92.

http://dx.doi.org/10.1016/j.jfoodeng.2010.03.031

17. Gennadios A, Handa A, Froning GW, Weller CL, Hanna MA. Physical properties of egg white-dialdehyde starch films. J Agric Food Chem. 1998;46:1297-302. http://dx.doi.org/10.1021/jf9708047

18. Kurt A, Kahyaoglu T. Characterization of a new biodegradable edible film made from salep glucomannan. Carbohydr Polym. 2014;104:50-8. http://dx.doi.org/10.1016/j.carbpol.2014.01.003

19. ASTM D882-12. Standard test method for tensile properties of thin plastic sheeting. West Conshohocken, PA, USA: American Society for Testing and Materials (ASTM International); 2012.

20. ASTM E96 / E96M-10. Standard test methods for water vapor transmission of materials. West Conshohocken, PA, USA: American Society for Testing and Materials (ASTM International); 2010.

21. AOCS Official Method Cd 8-53. Peroxide value: acetic acid-chloroform method. Official Methods and Recommended Practices of the American Oil Chemists' Society, the American Oil Chemists' Society AOCS, Champaign, IL, USA; 1997.

22. Gao X, Björk L, Trajkovski V, Uggla M. Evaluation of antioxidant actives of rosehip ethanol extracts in different test systems. J Sci Food Agric. 2000;80:2021-7. http://dx.doi.org/10.1002/1097-0010(200011)80:14<2021::AIDJSFA745 $>3.0 . C O ; 2-2$

23. Nakajima JI, Tanaka I, Seo S, Yamazaki M, Saito K. LC/PDA/ ESI-MS profiling and radical scavenging activity of anthocyanins in various berries. J Biomed Biotechnol. 2005;5:241-7. http://dx.doi.org/10.1155/S1110724304404045

24. Peng Y, Li Y. Combined effects of two kinds of essential oils on physical, mechanical and structural properties of chitosan films. Food Hydrocolloid. 2014;36:287-93. http://dx.doi.org/10.1016/j.foodhyd.2013.10.013

25. Ghasemlou M, Aliheidari N, Fahmi R, Shojaee-Aliabadi S, Keshavarz B, Cran MJ, Khaksar R. Physical, mechanical and 
barrier properties of corn starch films incorporated with plant essential oils. Carbohydr Polym. 2013;98:1117-26. http://dx.doi.org/10.1016/j.carbpol.2013.07.026

26. Shojaee-Aliabadi S, Hosseini H, Mohammadifar MA, Mohammadi A, Ghasemlou M, Ojagh SM, et al. Characterization of antioxidant-antimicrobial $\mathrm{k}$-carrageenan films containing Satureja hortensis essential oil. Int J Biol Macromol. 2013;52:116-24.

http://dx.doi.org/10.1016/j.ijbiomac.2012.08.026

27. Shojaee-Aliabadi S, Hosseini H, Mohammadifar MA, Mohammadi A, Ghasemlou M, Hosseini SM, Khaksar R. Characterization of $\mathrm{K}$-carrageenan films incorporated plant essential oils with improved antimicrobial activity. Carbohydr Polym. 2014;101:582-91.

http://dx.doi.org/10.1016/j.carbpol.2013.09.070

28. Tongnuanchan P, Benjakul S, Prodpran T. Physico-chemical properties, morphology and antioxidant activity of film from fish skin gelatin incorporated with root essential oils. J Food Eng. 2013;117:350-60.

http://dx.doi.org/10.1016/j.jfoodeng.2013.03.005

29. Hosseini SF, Rezaei M, Zandi M, Farahmandghavi F. Biobased composite edible films containing Origanum vulgare
L. essential oil. Ind Crop Prod. 2015;67:403-13. http://dx.doi.org/10.1016/j.indcrop.2015.01.062

30. Bonilla J, Atarés L, Vargas M, Chiralt A. Effect of essential oils and homogenization conditions on properties of chitosan-based films. Food Hydrocolloid. 2012;26:9-16. http://dx.doi.org/10.1016/j.foodhyd.2011.03.015

31. Tongnuanchan P, Benjakul S, Prodpran T. Structural, morphological and thermal behavior characterizations of fish gelatin film incorporated with basil and citronella essential oils as affected by surfactants. Food Hydrocolloid. 2014;41: 33-43.

http://dx.doi.org/10.1016/j.foodhyd.2014.03.015

32. Gencbay G, Turhan S. Proximate composition and nutritional profile of the Black Sea anchovy (Engraulis encrasicholus) whole fish, fillets and by-products. J Aquat Food Prod Technol. 2016; 25:864-74. http://dx.doi.org/10.1080/10498850.2014.945199

33. Espitia PJP, Avena-Bustillos RJ, Du WX, Chiou BS, Williams TG, Wood D, et al. Physical and antibacterial properties of açaí edible films formulated with thyme essential oil and apple skin polyphenols. J Food Sci. 2014;79:M903-10. http://dx.doi.org/10.1111/1750-3841.12432 